\title{
A clinico-epidemiological study of complicated external hernia
}

\author{
Lalit Kishore ${ }^{\mathrm{a},{ }^{*}}$, Sumit Naraniya ${ }^{\mathrm{b}}$, Deepak Verma ${ }^{\mathrm{a}}$, Parul Yadav ${ }^{\mathrm{a}}$, Ambrav Vedprakash $^{\mathrm{a}}$, Ratan Raj ${ }^{\mathrm{c}}$
}

${ }^{a}$ Department of Surgery, Dr. Sampurnanand medical college, Jodhpur, Rajasthan, India.

${ }^{b}$ Department of Surgery, Ravindra Nath Tagore medical college, Udaipur, Rajasthan, India.

${ }^{c}$ Department of Surgery, All India Institute of Medical Sciences, Jodhpur, Rajasthan, India.

\begin{abstract}
Background: Abdominal wall hernias are among the most commonly encountered surgical problem. Irreducibility, obstruction, and strangulation are its commonest complications which usually presents as acute emergencies. Emergency repair of complicated hernias is associated with poor prognosis and a high rate of postoperative complications even with better care, improved anesthetic management and advanced surgical techniques.

Methods: The aim of the study was to evaluate incidence, morbidity, and mortality in complicated hernia and to compare with it non-complicated hernia. This study was conducted in the Department of General Surgery, Dr. Sampurnanand Medical College, Jodhpur, Rajasthan, from July 2018 to December 2019 on twenty-eight patients of complicated hernia and compared with similar no of uncomplicated hernia patients.

Results: The mean age of the patients was 52 years with male to female ratio of 11:3 in the complicated external hernia group. The majority of the patient (60.7\%) underwent herniorrhaphy, followed by hernioplasty $(14.3 \%)$. Most of the patients (89.2\%) survived without any post-operative morbidity, $7.1 \%$ of them developing wound sepsis while $3.5 \%$ of patients died after surgery due to septic shock.

Conclusion: Complicated external hernias occur in all age groups but are more common in older age and show preponderance in males. All patients present with irreducible swelling with no cough impulse. The indirect inguinal hernia is the most common type and herniorrhaphy is the most preferred operative procedure in the complicated hernia. Wound sepsis was the most common complication. Morbidity and mortality may be attenuated with proper surgical and post-operative management.
\end{abstract}

Keywords: Abdominal wall hernia; complicated hernia; herniorrhaphy; hernia

\section{INTRODUCTION}

Abdominal wall hernias are among the most common of all surgical problems. Hernias are relatively innocuous diseases in itself and they commonly present as uncomplicated reducible swellings and can be operated in an elective setting with negligible morbidity and mortality ${ }^{[1]}$. When they complicate as irreducibility, obstruction and strangulation, and it compels the patient to present as an emergency ${ }^{[2,3]}$, and management

\footnotetext{
* Corresponding author: Lalit Kishore

Mailing address: Department of Surgery, Dr. Sampurnanand medical college, Jodhpur, Rajasthan, India.

E-mail: drlalitkishore@gmail.com

Received: 01 September 2020 / Accepted: 23 November 2020
}

of these cases are associated with high morbidity and mortality in both developing and developed countries ${ }^{[4,5]}$. A hernia is termed as complicated when it becomes irreducible, incarcerated, strangulated or recurrent. Complication becomes grievous when the blood supply of its contents is seriously impaired, rendering gangrene imminent.

The reason for the hernia to go into complications is because of the hesitancy of the patient to come out with complaints and refusal for surgery in an early stage. The complications make an easily treatable condition into a life-threatening one. Early diagnosis and elective repair is a safe and effective strategy for patients of all ages that avoid incarceration, strangulation and their complications ${ }^{[6]}$. Although we have made great progress in treating hernia the management of its complications has progressed only a little. The aim 
of the study was to evaluate incidence, morbidity and mortality in complicated hernia and to compare with it non-complicated hernia.

\section{MATERIAL AND METHODS}

This observational comparative study was conducted in the Department of General Surgery, Dr. S N Medical College, Jodhpur, Rajasthan from July 2018 to December 2019. All patients with groin, epigastric, umbilical/ Para-umbilical, lumbar, or any type of hernia with age more than 16 years presented with pain with irreducibility, features s/o intestinal obstruction-like Pain abdomen, abdominal distension, vomiting, constipation/obstipation, hypotension, tachycardia shock and features s/o peritonitis were included in the study. All patients studied in reference to symptoms, duration of symptoms, type of hernia, management, morbidity and mortality, and hospital stay. Patients were divided into Group A (complicated) and Group B (uncomplicated). Patients below the age of 16 years and who refused to give consent were excluded from the study.

All patients were subjected to basic hematological \& necessary radiological investigations (USG), chest Xray, and abdomen X-ray erect view. All symptomatic patients were assessed for emergency surgery and written informed consent was obtained. Under general or spinal anesthesia, transverse/inguinal/midline incision was made according to clinical presentation. Intraoperative finding like a site of constriction, contents of the sac, viability of contents was noted then contents were reduced, the sac is ligated and hernioplasty was performed. If the content was gangrenous intestine, Resection and anastomosis were done followed by Herniorapphy (modified bassini repair). Postoperatively managed according to standard protocol. Statistical analysis was performed using Chi-square. $\mathrm{P}<0.05$ was considered statistically significant.

\section{RESULTS}

Twenty-eight patients were admitted from July 2018 to December 2019 with the complicated external hernia and were considered as group A. Total of 250 cases of uncomplicated external hernia were admitted from July 2018 to December 2019 out of the 28 patients were randomly selected for study and considered as group B.

Complicated external hernias were observed between 66 to 75 years (35.7\%). Although complication was reported in as young as 22 years to 85 years with a mean
Table 1. Age distribution.

\begin{tabular}{lll}
\hline \multirow{2}{*}{ Age (years) } & \multicolumn{2}{c}{ Number of patients } \\
\cline { 2 - 3 } & Complicated(Group A) & Uncomplicated(Group B) \\
\hline $16-25$ & $01(3.5 \%)$ & $00(0 \%)$ \\
$26-35$ & $01(3.5 \%)$ & $04(14.3 \%)$ \\
$36-45$ & $05(17.6 \%)$ & $05(17.6 \%)$ \\
$46-55$ & $03(10.7 \%)$ & $04(14.3 \%)$ \\
$56-65$ & $06(21.4 \%)$ & $06(21.4 \%)$ \\
$66-75$ & $10(35.7 \%)$ & $08(28.6 \%)$ \\
$76-85$ & $02(7.1 \%)$ & $01(3.5 \%)$ \\
Total & $28(100 \%)$ & $28(100 \%)$ \\
\hline
\end{tabular}

Chi-square $=3.498, \mathrm{df}=6, \mathrm{p}=0.744$.

age of 52 years. In group B, patients were in the age range of 26-85 years with a mean age of 55 years, but here also the majority of patients (28.6\%) belonged to the 66-75 years age group. On applying a Chi-square test, $\mathrm{P}=0.744$, statistically not significant(Chi-sqare $=$ 3.498, $d f=6, P=0.744$.), shown in table 1 .

Table 2. Distribution of type of hernia.

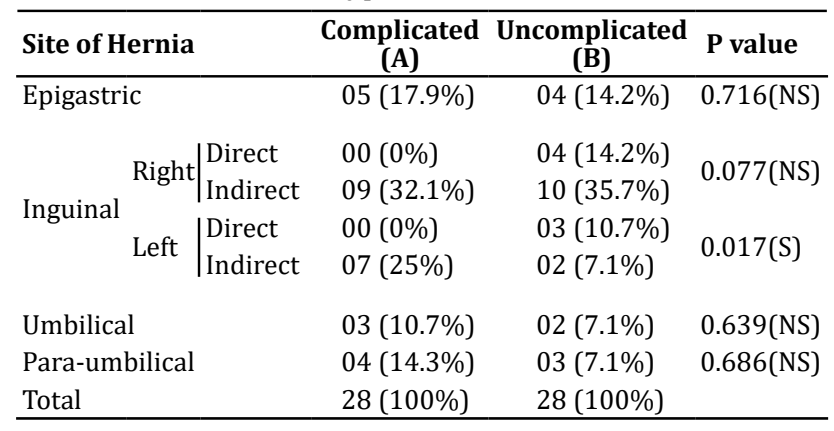

In our study, the majority of patients $(57.1 \%$ complicated, $67.8 \%$ uncomplicated) were found to be having inguinal hernia. Among them right-sided direct inguinal hernias and left side indirect were predominant. All the other forms of hernia except inguinal were observed to be more associated with complications viz, Epigastric (17.9\%), para-umbilical (14.3\%) and umbilical hernias $(10.7 \%)$ were observed as complicated hernia though statistically, no significant difference found to be there between complicated and uncomplicated forms, shown in table 2.

Table 3. Operative procedure performed.

\begin{tabular}{lcc}
\hline Operative procedure & $\begin{array}{c}\text { Complicated } \\
\text { hernia (A) }\end{array}$ & $\begin{array}{c}\text { Uncomplicated } \\
\text { hernia(B) }\end{array}$ \\
\hline $\begin{array}{l}\text { Herniorrhaphy } \\
\begin{array}{l}\text { Exploratory laparotomy } \\
\text { and repair }\end{array}\end{array}$ & $04(60.7 \%)$ & $02(7.1 \%)$ \\
$\begin{array}{l}\text { Exploratory laparotomy with } \\
\text { resection and end to end } \\
\text { anastomosis with herniorrhaphy }\end{array}$ & $03(10.7 \%)$ & $00(0 \%)$ \\
\begin{tabular}{l} 
Mesh Hernioplasty \\
\hline
\end{tabular} & $04(14.3 \%)$ & $26(92.9 \%)$ \\
\hline
\end{tabular}

Chi-square $=34.98, \mathrm{df}=3, \mathrm{p}<0.0001(\mathrm{~S})$. 
Most patients of complicated hernia underwent herniorrhaphy $(60.7 \%)$, followed by hernioplasty (14.3\%), exploratory laparotomy with repair $(14.3 \%)$, and resection of a gangrenous segment with end to end anastomosis with herniorrhaphy $(10.7 \%)$. While most of the patients with uncomplicated hernia underwent mesh hernioplasty and this difference between both groups of hernias was found to be statistically significant (Chi-square $=34.98, \mathrm{df}=3, \mathrm{p}<0.0001$ ), shown in table 3.

Table 4. Post-operative complications.

\begin{tabular}{lll}
\hline $\begin{array}{l}\text { Post operative } \\
\text { Complication }\end{array}$ & \multicolumn{2}{c}{ Number of patients } \\
\cline { 2 - 3 } & Complicated(A) & Uncomplicated(B) \\
\hline No complication & $25(89.3 \%)$ & $28(100 \%)$ \\
Wound sepsis & $02(07.1 \%)$ & $00(0 \%)$ \\
Shock & $01(3.5 \%)$ & $00(0 \%)$ \\
\hline
\end{tabular}

Most of the patients with complicated hernia (89.3\%) survived without any post-operative morbidity, while only $7.1 \%$ of them developing wound sepsis, and 3.5\% of patients developed post-operative shock. $3.5 \%$ of patients expired after surgery due to septic shock. shown in table 4.

Table 5. Hospital stay.

\begin{tabular}{lll}
\hline $\begin{array}{l}\text { Duration of stay } \\
\text { (days) }\end{array}$ & Complicated(A) & Uncomplicated(B) \\
\hline 1 to 3 & $02(7.1 \%)$ & $00(0 \%)$ \\
4 to 7 & $14(50 \%)$ & $26(92.9 \%)$ \\
8 to 10 & $09(32.1 \%)$ & $02(7.1 \%)$ \\
11 to 15 & $01(3.5 \%)$ & $00(0 \%)$ \\
$>15$ & $02(7.1 \%)$ & $00(0 \%)$ \\
\hline
\end{tabular}

Chi-square $=13.05, \mathrm{df}=4, \mathrm{p}<0.010(\mathrm{~S})$.

Most operated patients of complicated hernia (50\%) spent 4 to 7 days in the hospital, while $7.1 \%$ of patients required a hospital stay for more than 15 days, and another $7.1 \%$ patients required 1-3 days of stay. In the case of the uncomplicated hernia group, the majority of patients(92.9\%) had a similar duration hospital stay of 4-7 days, shown in table 5 .

\section{DISCUSSION}

The external abdominal wall hernia is most commonly encountered in surgical practices. When they presented as complicated hernia, the prognosis is poor even after standard protocol management. In the present study, complicated external hernias were observed between 66 to 75 years (35.7\%). Although complication was reported in as young as 22 years to 85 years with a mean age of 52 years. In group B, patients were in the age range of 26-85 years with a mean age of 55 years. Kulah et al. ${ }^{[7]}$ observed the mean age for complicated external hernia was 55 years, with $42.9 \%$ of patients aged more than 60 years. Alavarez et al. ${ }^{[8]}$ also observed that $66.7 \%$ of cases were more than 65 years of age.Hence, it is evident from the present study the incidence of complications increases with advancing age. In the present study, the incidence of complicated external hernia was more in males $(78.6 \%)$, with male to female ratio of $11: 3$, indicating a high incidence of complicated external hernia among male patients. Similar male predominance was observed in other studies by Kulah et al. ${ }^{[7]}$ (65\%), Alvarez et al. ${ }^{[8]}$ (52.4\%), Hariprasad et al. ${ }^{[9]}$ (95\%), and Prakash et al. ${ }^{[10]}$ (94.3\%). In the present study, $57.1 \%$ of patients had indirect inguinal hernias. Among them, right-sided indirect inguinal hernias were predominant (32.1\%). Epigastric (17.9\%), para-umbilical (14.3\%) and umbilical hernias $(10.7 \%)$ were also observed as complicated hernia.

In the present study, $64.3 \%$ of patients had irreducible hernia, $28.9 \%$ had obstructed hernia and $7.1 \%$ had strangulated hernia depicted in Figure 1. Hariprasad et al. ${ }^{[9]}$ observed incarceration in $70 \%$ of cases and strangulation in $30 \%$ of cases. Prakash ${ }^{[10]}$ observed $23 \%$ of patients of irreducible hernia, $63 \%$ of obstructed hernia, and $14 \%$ of strangulated hernia. Kappikeri et al. ${ }^{[11]}$ observed $44 \%$ of cases of irreducible hernia, 36\% of obstructed hernia, and $20 \%$ of cases of strangulated hernia. Kulah et al. ${ }^{[7]}$ observed $41.6 \%$ of patients with irreducible hernia, $19.7 \%$ with obstructed hernia, and $38.7 \%$ with strangulated hernia.

In our study, $57.1 \%$ of patients had indirect complicated inguinal hernia where the deep ring was the commonest site for constriction of the hernia, followed by epigastric $17.9 \%$, para-umbilical $14.3 \%$ and umbilical hernia $10.7 \%$. Rectus sheath was the commonest site

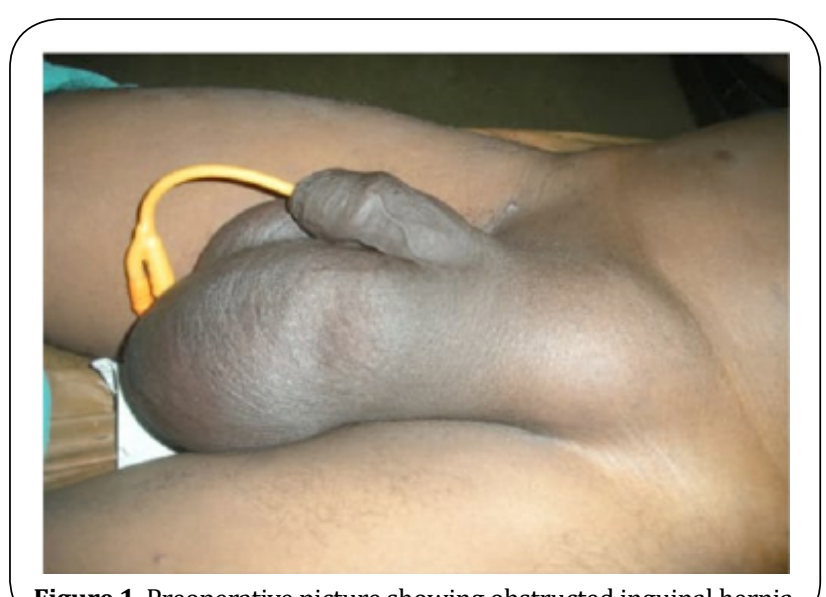

Figure 1. Preoperative picture showing obstructed inguinal hernia. 
of obstruction in epigastric, umbilical, and paraumbilical hernia. Similarly, Prakash et al. ${ }^{[10]}$ reported deep ring as the commonest site of constriction (71.4\%) in groin hernia. Hariprasad et al. ${ }^{[9]}$ also concluded that the site of obstruction in most patients was seen at the deep inguinal ring (92.5\%), whereas in the case of direct inguinal hernia obstruction was at the neck of the sac.

Omentum alone was the commonest content of the complicated hernial sac (46.4\%), followed by omentum with bowel loop (32.1\%), small bowel only (10.7\%), colon only $(10.7 \%)$ and omentum with colon $(14.3 \%)$. Hariprasad et al. ${ }^{[9]}$ found that only omentum as the viable content in most (32.5\%) cases, followed by omentum and small bowel in 30\% cases, small bowel alone and sigmoid colon one case each, and large bowel with omentum in $10 \%$ cases. Andrew et al. ${ }^{[12]}$ reported the small bowel as the commonest content of incarcerated inguinal hernia; followed by omentum. In the study of Kulah et al. ${ }^{[7]}$ also, the contents of the hernial sac were only ileum in $39.7 \%$ patients, only omentum in $27.1 \%$ patients, ileum with omentum in $10.9 \%$ patients, and only colon in $28.5 \%$ patients. Alvarez et al. ${ }^{[8]}$ found the only omentum as the content of the hernial sac in $37.4 \%$ patients, only ileum in $27.2 \%$ patients, ileum with omentum in $10.8 \%$, only colon in $4.1 \%$, colon with omentum is $1.4 \%$. Prakash et al. ${ }^{[10]}$ found small bowel as the commonest content $(74.3 \%)$ followed by omentum (25.7\%). Kappikeri et al. ${ }^{[11]}$ observed the small intestine to be the commonest content of the hernia sac (54\%), followed by the omentum (18\%). In the control group, most of the patients (92.9\%) had omentum as the content of the hernial sac, followed by pre-peritoneal fat in epigastric hernia (7.1\%).

In the present study, only $7.1 \%$ had gangrenous content, the rest of the patients (92.9\%) had viable content depicted in Figure 2. Kappikeri et al. ${ }^{[11]}$ observed the non-viable content in $12 \%$ of patients. Alvarez et al. ${ }^{[8]}$ observed that $12.9 \%$ of patients had gangrenous content in the sac. Hariprasad et al. ${ }^{[9]}$ also observed the non-viable bowel content in $22.5 \%$ of cases. In the control group, all patients $(100 \%)$ had viable content in their sacs.

Most of the patients (60.7\%) underwent herniorrhaphy, followed by hernioplasty (14.3\%), exploratory laparotomy with repair (14.3\%), and resection of gangrenous segment with end to end anastomosis with herniorrhaphy (10.7\%) shown in Table 3. Hariprasad et al. ${ }^{[9]}$ observed that herniorrhaphy was done in all cases $(100 \%)$ for closure, and modified Bassini's repair was performed in inguinal hernias. Laparotomy and repair was done in $25 \%$ of cases. Prakash et al. ${ }^{[10]}$ also reported that the optimum procedure for hernia repair was herniorrhaphy which was done in $82.8 \%$ of cases whereas herniorrhaphy along with resection anastomosis was done in $8.6 \%$ cases and herniorrhaphy along with the repair was done in $8.6 \%$ of cases. Kappikeri et al. ${ }^{[11]}$ concluded that herniorrhaphy was the commonest (74\%) surgical procedure performed for complicated inguinal hernias, while $14 \%$ of patients underwent hernioplasty, $12 \%$ of patients of strangulation with non-viable bowel required resection and anastomosis followed by herniorrhaphy. In the control group, most patients $(92.9 \%)$ underwent mesh hernioplasty, while $7.1 \%$ underwent herniorrhaphy.

In our study, $89.2 \%$ survived without any post-operative morbidity, while only $7.1 \%$ of them developing wound sepsis and $3.5 \%$ of patients died after surgery due to septic shock depicted in Table 4.

Haapaniemi et al. ${ }^{[13]}$ observed that $5.5 \%$ of cases died, $3 \%$ of them due to associated medical illness and $2.5 \%$ from septicemia. He found that mortality increase in emergency repair of hernia and in patients who had a bowel resection. Hariprasad et al. ${ }^{[9]}$ also observed that the common postoperative complication was wound infection $(22.5 \%)$ and scrotal seroma (17.5\%) followed by scrotal hematoma (7.5\%). Septicemia, multi-organ failure, and death occurred in $2.5 \%$ of cases. Prakash et al. ${ }^{[10]}$ observed wound infection as a complication in $11.5 \%$ of patients. Kappikeri et al. ${ }^{[11]}$ observed $6 \%$ mortality among the cases, $2 \%$ of patients due to ischemic heart disease, while $4 \%$ of cases expired following bowel resection in a strangulated hernia. In Group $B$, none of the patients ( $0 \%$ ) had encountered any post-operative complication and all patients (100\%)

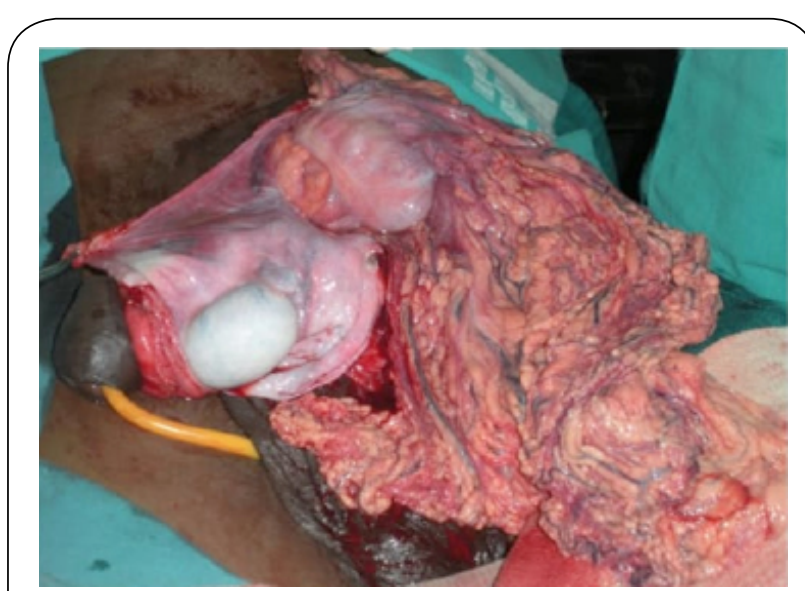

Figure 2. Intra-operative photo showing viable colon and omentum as content of sac. 
survived after surgery.

The duration of most operated patients (50\%) was 4 to 7 days in hospital, while $7.1 \%$ patients required a hospital stay for more than 15 days, and another $7.1 \%$ patients required 1-3 days of stay shown in Table 5. In the study of Kappikeri et al. ${ }^{[11]}$, most of the patients (46\%) were discharged within 11-15 days. In the control group, most patients (92.9\%) spent 4 to 7 days in hospital, with $7.1 \%$ patients required between 8 to 10 days of stay. All patients were followed up to 6 months, however, no complications were noted.

\section{CONCLUSION}

Complicated external hernias occur in all age groups but are more common in older age and show preponderance in males. All patients present with irreducible swelling with no cough impulse. The indirect inguinal hernia is the commonest type and right-sided inguinal hernia predominated as compared with left. Herniorrhaphy was the most preferred operative procedure in complicated hernia. Morbidity and mortality may be attenuated with proper surgical and post-operative management.

\section{DECLARATIONS}

\section{Financial support}

No financial assistance was taken.

\section{Conflict of interest}

The author declares that there is no conflict of interest.

\section{Ethical disclosure}

Ethical committee approval was obtained prior to study.

\section{REFERENCES}

1. Zinner, M.J., Ashley, S.W., Hernias. (2007)Maingot's Abdominal Operations. Journal of the American College of Surgeons,12th Ed: 103-140.

2. Martínez-Serrano, M. Á., Pereira, J. A., Sancho, J. J., López-Cano, M., Bombuy, E., Hidalgo, J., \& Study Group of Abdominal Hernia Surgery of the Catalan Society of Surgery. (2010). Risk of death after emergency repair of abdominal wall hernias. Still waiting for improvement. Langenbeck's Archives of Surgery, 395(5), 551-556.

3. Derici, H., Unalp, H. R., Bozdag, A. D., Nazli, O., Tansug, T., \& Kamer, E. (2007). Factors affecting morbidity and mortality in incarcerated abdominal wall hernias. Hernia, 11(4), 341-346.

4. Tsumura, H., Ichikawa, T., Hiyama, E., Murakami, Y., \& Sueda, T. (2004). Systemic inflammatory response syndrome (SIRS) as a predictor of strangulated small bowel obstruction. Hepato-gastroenterology, 51(59), 13931396.

5. Jancelewicz, T., Vu, L. T., Shawo, A. E., Yeh, B., Gasper, W. J., \& Harris, H. W. (2009). Predicting strangulated small bowel obstruction: an old problem revisited. Journal of Gastrointestinal Surgery, 13(1), 93-99.

6. Rai, S., Chandra, S. S., \& Smile, S. R. (1998). A study of the risk of strangulation and obstruction in groin hernias. Australian and New Zealand journal of surgery, 68(9), 650-654.

7. Kulah, B., Kulacoglu, I. H., Oruc, M. T., Duzgun, A. P., Moran, M., Ozmen, M. M., \& Coskun, F. (2001). Presentation and outcome of incarcerated external hernias in adults. The American journal of surgery, 181(2), 101-104.

8. Alvarez, J. A., Baldonedo, R. F., Bear, I. G., Solis, J. A. S., Alvarez, P., \& Jorge, J. I. (2004). Incarcerated groin hernias in adults: presentation and outcome. Hernia, 8(2), 121-126.

9. Hariprasad, S., \& Srinivas, T. (2017). Clinical study on complicated presentations of groin hernias. Int J Res Med Sci, 5(8), 3303-8.

10. Prakash, S., Samraj, A., \& Muthukumaran, G. (2017). A study on groin hernias presenting as acute surgical emergencies in adults. International Surgery Journal, 4(12), 3866-3872.

11. Kappikeri, V., \& Kalaskar, N. N. (2019). A clinical study of complicated inguinal hernias. International Surgery Journal, 6(5), 1608-1612.

12. Andrews, N. J. (1981). Presentation and outcome of strangulated external hernia in a district general hospital. British Journal of Surgery, 68(5), 329-332.

13. Haapaniemi, S., Sandblom, G., \& Nilsson, E. (1999). Mortality after elective and emergency surgery for inguinal and femoral hernia. Hernia, 3(4), 205-208. 